\title{
Prognostic value of lymphocyte-monocyte ratio at diagnosis in Hodgkin lymphoma: a meta-analysis
}

\author{
Shing Fung Lee ${ }^{1,4^{*}}$, Ting Ying $\mathrm{Ng}^{1}$ and Devon Spika $2,3,4$
}

\begin{abstract}
Background: Prognoses of most adult Hodgkin lymphoma ( $\mathrm{HL}$ ) patients are excellent; most of them can achieve permanent remission that can be considered cured. However, many are under-treated or over-treated by standard modern therapies. An accurate determination of prognosis may allow clinicians to design personalised treatment according to individual risk of disease progression and survival. Lymphocyte monocyte ratio (LMR) at diagnosis has been investigated as a prognostic biomarker in patients with HL. Our objective with this meta-analysis was to explore the prognostic value of the LMR at diagnosis in adult $\mathrm{HL}$, by investigating the association between LMR and survival outcomes.

Methods: PUBMED and EMBASE were searched for relevant articles. Survival outcomes that we investigated included overall survival (OS), progression-free survival (PFS), event-free survival (EFS), lymphoma-specific survival (LSS), and time to progression (TTP). No restriction to the language, date, study country, or sample size was applied. Final search of databases was performed on 2 April 2018. We performed random-effects meta-analysis to aggregate and summarise the results from included studies, where four or more studies on a particular outcome were available.

Results: A total of eight studies (all retrospective cohort studies) involving $3319 \mathrm{HL}$ patients were selected for analysis. All studies except one reported the effect of LMR on OS; five reported on PFS, three reported on TTP and LSS, respectively, and one reported on EFS. The pooled estimates showed low LMR was associated with poor OS (hazard ratio $[H R] 2.67,95 \% \mathrm{Cl} 1.67,4.26)$ and PFS (HR 2.19, 95\% Cl 1.46, 3.29). Subgroup analyses of OS stratified by LMR cut-off values and sample sizes both indicated that low baseline LMR was associated with poorer prognosis.

Conclusions: Low LMR at diagnosis was associated with poor OS and PFS in HL. LMR is easy and cheap to determine and has a potential role in daily clinical management. More studies are needed to validate this biomarker and explore its interaction with known prognostic factors.
\end{abstract}

Keywords: Meta-analysis, Lymphocyte, Monocyte, Hodgkin lymphoma, Prognosis

\section{Background}

Hodgkin lymphoma (HL) is a type of lymphoma of B-cell origin. About $15 \%$ of lymphomas are HL [1]. Two major subtypes of $\mathrm{HL}$ are classical $\mathrm{HL}$ and nodular lymphocyte predominant Hodgkin's lymphoma (NLPHL). Classical HL is further subclassified into four histological subtypes: nodular-sclerosis classical HL, lymphocyte-rich

\footnotetext{
* Correspondence: leesfm@ha.org.hk

'Department of Clinical Oncology, Tuen Mun Hospital, New Territory West

Cluster, Hospital Authority, Tuen Mun, Hong Kong

${ }^{4}$ London School of Hygiene and Tropical Medicine, London, UK

Full list of author information is available at the end of the article
}

classical HL, mixed-cellularity classical HL, and lymphocytedepletion classical HL [2]. HL is one of the most common malignancies in young adults aged $20-40$ years [3]. Only about $15-35 \%$ of HL patients are older than age 60 years [3-6]. This variation in incidence by age at diagnosis is represented in Western countries by the bimodal age-incidence curve showing two peaks, first at around age 20 years, and second at around age 65 years [7]. While the bimodal curve is a defining epidemiological feature of HL, its shape varies significantly by race, socioeconomic status, geography, time,

(c) The Author(s). 2019 Open Access This article is distributed under the terms of the Creative Commons Attribution 4.0 International License (http://creativecommons.org/licenses/by/4.0/), which permits unrestricted use, distribution, and 
sex, and histological subtype [8-10]. For example, for calendar years 2010 to 2014 the age standardised incidence rates for Asian and Pacific islanders and non-Hispanic whites in the US were 1.2 and 2.9 per 100,000, respectively [9].

Standard treatment depends on stage and other clinical information. It usually consists of two to 8 cycles of chemotherapy followed by radiotherapy in selected patients [3]. The treatment algorithm is largely determined by clinical parameters such as age, stage and size of disease bulk. More than $95 \%$ of early stage HL, and up to $80-90 \%$ of intermediate or advanced stage patients can achieve permanent remission and can be considered cured with modern therapy [11]. However, at least 10$20 \%$ of patients in all stages may be under- or over-treated [11]. It is important at the time of diagnosis to determine the prognosis accurately. This allows clinicians to refine and tailor the treatment strategy, to avoid undertreatment (such as inadequate cycles of chemotherapy or exposure to ineffective cytotoxic agents) for patients at higher risk of disease relapse or increased resistance to chemotherapy and radiotherapy, and prevent overtreatment for those with a high chance of having their lymphoma cured, who may be suitable for less toxic therapies [11-13]. Patients who have their diseases relapsed after standard first line therapy need salvage treatment with high dose chemotherapy followed by autologous stem cell transplantation, and only half are successful treated [14]. On the other hand, HL long-term survivors have a two to four times increased risk of a second malignancy and cardiovascular disease compared with healthy members of the general population. This is important especially when most HL patients are young adults, and these long-term toxicities are associated with the anti-cancer treatment $[15,16]$. One study evaluating the outcomes of decreased treatment intensity in a subgroup of early stage HL patients showed that the treatment effectiveness was not compromised when therapy was de-escalated, and more than $50 \%$ of all deaths during long-term follow-up were possibly related to the delivered treatment [17].

The goal of using prognostic markers to predict outcomes is to achieve a personalised approach: allowing us to provide more intensive or novel therapies (or avoid exposure to ineffective treatments) to patients with more aggressive disease, and to de-escalate therapy to patients with a high probability of achieving long-term remission, to spare the treatment toxicity.

The international prognostic score (IPS) is a standard stratification system for advanced classical HL [18]. Prognostic factors affecting clinical outcomes of NLPHL are similar to those included in the IPS [19-21]. For early stage HL, IPS is a less appropriate risk stratification system and other prognostic scoring systems can be used, such as those from the German Hodgkin Study Group (GHSG) [17], European Organisation for Research and Treatment of Cancer (EORTC) [22], and National Cancer Institute of Canada (NCIC) [23]. These prognostic systems are based mainly on clinical parameters, such as Ann Arbor staging, and tumour sizes $[17,18,22,23]$. They do not consider the host immune status and tumour microenvironment, which can be variable among patients with similar clinical characteristics.

A gene expression profiling study has shown that a raised number of tumour-associated macrophages (TAMs) in a pre-treatment lesional tissue sample is associated with lower survival in patients with HL [24]. These macrophages are derived from peripheral blood monocytes [25] and have been positively associated with the percentage of peripheral blood monocytes [26]. They can secrete trophic factors (that affect tumour microenvironment), which have a role in the process where tumour cells interact with stromal and immune cells, including macrophages, B-cells and T-cells. The interaction in turn leads to neovascularisation and tumour growth [27-30]. Lymphocytes also have a role in immunosurveillance: the absolute lymphocyte count (ALC) has been shown to be a surrogate of host immune status and is an independent prognostic factor in HL [31].

Many of the advanced techniques for prognostication, including gene expression profiling [24] and immunohistochemical analysis [32, 33] have been studied. These are, however, costly and difficult to perform and interpret. A prognostic factor that is easily determined and widely available is needed.

Peripheral blood lymphocyte-to-monocyte ratio (LMR) at diagnosis may reflect the interaction between host immunity, represented by lymphocytes, and the tumour microenvironment, represented by monocytes. The peripheral blood count and cell count ratio can be determined readily and inexpensively by a standard automated complete blood count machine. Recent studies have indicated that peripheral blood LMR at diagnosis can predict long-term outcomes in haematological malignancies, including follicular lymphoma [34], diffuse large B-cell lymphoma [35], and NK/T cell lymphoma [36].

In HL, the consistency and magnitude of the prognostic value of LMR is controversial. Some studies have demonstrated a correlation between baseline LMR and survival outcomes, while one did not [37]. Different studies have, however, used different LMR cut-off values. One meta-analysis reported the prognostic value of LMR in various cancer types, and found that low LMR at diagnosis was associated with poorer cancer-specific survival and PFS in HL [38]. Since its publication in 2016, more studies on the prognostic role of LMR have been published, and three out of the seven analysed 
papers on HL were abstracts only. An updated analysis is needed to appraise and summarise the evidence.

This study aims to quantify the relationship between LMR at diagnosis and survival outcomes in adult HL, and to explore the impact of study characteristics on the prognostic value of LMR, by using meta-analytic techniques.

\section{Methods}

In this study, we used meta-analysis to investigate the relationship between LMR at diagnosis and survival outcomes in adult HL. Specific outcomes considered were overall survival (OS), progression-free survival (PFS), event-free survival (EFS), lymphoma-specific survival (LSS), and time-to-progression (TTP). Definitions of the different survival endpoints are summarised in Table 1 [39].

Analysis and reporting were performed according to the Preferred Reporting Items for Systematic reviews and Meta-Analyses (PRISMA) and Meta-analyses of Observational Studies guidelines [40, 41]. Two reviewers (SFL and TYN) independently performed the literature search, assessed study eligibility, extracted the relevant data, and performed risk of bias assessment, following the strategy set out below. Any disagreement between the reviewers was resolved through discussion and consensus.

\section{Search strategy}

Studies were identified through a systematic search of the EMBASE and MEDLINE databases, via the OVID platform. The search terms included "lymphocyte monocyte ratio" AND "Hodgkin lymphoma" (OR "Hodgkin's lymphoma"). The search strategies for each database are described in the Additional file 1: Appendix S1. We did not apply restrictions to the language, date, study country, or sample size in our search. We performed the final search of all databases on 2 April 2018. Reference lists of relevant studies were also reviewed for possibly suitable articles. For non-English literature, we have used Google Translate for translation before we determined the eligibility for inclusion. Academic experts on lymphoma

Table 1 Definitions of survival endpoints

\begin{tabular}{ll}
\hline Endpoints & Definition \\
\hline Overall survival & Entry into study until death as a result of any cause \\
$\begin{array}{l}\text { Progression-free } \\
\text { survival }\end{array}$ & $\begin{array}{l}\text { Entry into study until lymphoma progression or } \\
\text { death as a result of any cause }\end{array}$ \\
Event-free survival & $\begin{array}{l}\text { Entry into study until any treatment failure including } \\
\text { lymphoma progression, or discontinuation of } \\
\text { treatment for any reason including death }\end{array}$ \\
$\begin{array}{l}\text { Lymphoma-specific } \\
\text { survival }\end{array}$ & $\begin{array}{l}\text { Entry into study until time to death as a result of } \\
\text { lymphoma }\end{array}$ \\
Time-to-progression & $\begin{array}{l}\text { Entry into study until time to lymphoma } \\
\text { progression or death as a result of lymphoma }\end{array}$ \\
\hline
\end{tabular}

were contacted to identify any additional or unpublished data.

\section{Inclusion and exclusion criteria}

Studies were considered eligible for inclusion if: 1) they reported data from an original, peer-reviewed study (i.e. not case reports, comments, conference abstracts, or review articles), 2) the study design included a prospective or retrospective cohort, case-control study, or randomised controlled trial, 3) they studied histologically proven HL in patients aged 18 years or older receiving primary treatment, 4) reported LMR as a dichotomised variable at diagnosis before specific anti-cancer treatment, 5) reported the prognostic outcome in terms of OS, PFS, EFS, LSS, or TTP, and 6) reported hazard ratios (HRs) of survival end-points according to high and low LMR with $95 \%$ confidence intervals $(\mathrm{CI})$, or provided data for HR calculation. We excluded studies that did not provide quantification data or sufficient statistical parameters for analysis, or reported exclusively on patients aged below 18 years. We also excluded duplicate reports and studies covering overlapping populations. In cases where the same study population was reported on more than once, we included the most recent publication.

\section{Data extraction}

We extracted information from the included studies on first author of the study, year of publication, journal, study design, country of study population, sample size, time period of study, median age and age range in the sample, sex distribution, cancer stage, IPS, median LMR, LMR cut-off value used, ratio of high to low LMR, survival outcomes investigated and hazard ratios (HR) for these, treatment modalities, and confounding factors adjusted for. We derived standard deviations and standard errors from the $p$-values, according to the instructions in the Cochrane Handbook for Systematic Reviews of Interventions [42].

\section{Quality and risk of bias assessment}

We used the Quality In Prognosis Study (QUIPS) tool to assess the quality of each included study. The QUIPS tool was specifically developed for use in reviewing prognosis studies, which are prone to methodological challenges such as variation in methods and poor reporting, which may introduce important biases [43]. We assessed the quality of each study by evaluating the risk of bias in six domains: study participation and attrition, prognostic factor measurement, outcome measurement, confounding measurement, and statistical analysis and reporting. We assigned an overall grade for the risk of bias in the study (low, medium, high) based on the assessed risk of bias in each of the six domains. We adapted the QUIPS tool to the purpose of our analysis, by deciding a priori 
on the most relevant domains (outcome measurement, study confounding, and statistical analysis and reporting) to rate the overall risk of bias in the included studies [43]. We considered the inclusion of important potential confounding factors and the performance of multivariate analysis as important quality criteria for studies that investigated the prognostic significance of LMR in adult HL patients.

\section{Statistical analysis}

This meta-analysis investigated the relationship between LMR at diagnosis and HL survival outcomes (OS, PFS, EFS, LSS, and TTP). The main summary statistics used in this meta-analysis were thus the relevant HRs for each survival outcome and their corresponding 95\% CIs. Meta-analysis was conducted if a minimum of four studies were identified for a particular survival outcome. Heterogeneity between effect estimates was quantified. First, we determined the degree of between-study variability using the Cochran Q statistical test [44], we used a less conservative $p$-value of $<0.10$ to indicate significant heterogeneity because of its low power when the number of studies is small [44]. Second, the $\mathrm{I}^{2}$ statistic was calculated to estimate the proportion of total variation across studies due to statistical heterogeneity but not chance [45]. $\mathrm{I}^{2}$ values of 25,50 , and $75 \%$ represent low, moderate, and high levels of heterogeneity, respectively.

We used a random-effects model to calculate a meta-analytic summary estimate of each HR, with $95 \%$ CIs, using DerSimonian and Laird's method [46]. Random-effects meta-analysis takes into account statistical heterogeneity between studies, which can result from differences in the measurement of outcomes, interventions received by patients, or patient characteristics between studies [46]. Adjusted estimates were used in the analysis to account for confounding.

We performed subgroup analyses by LMR cut-off value and sample size, because it was expected that these factors would be different among studies and might potentially explain the varying survival outcomes. Sensitivity analyses were performed to examine statistical heterogeneity by omitting each study sequentially and assessing the effect estimate from remaining studies. Publication bias was assessed qualitatively using funnel plots of the logarithmic HRs versus their standard errors $[47,48]$. We deemed the risk of publication bias to be low if the plot resembled a symmetrical inverted funnel [49]. We assessed publication bias quantitatively using the Egger regression test, and deemed publication bias as strongly suggested if $p \leq 0.10$ [48].

All $p$-values were two-tailed. We considered a p-value of $<0.05$ statistically significant, except when investigating heterogeneity and publication bias. All analyses and graphs were produced using Stata version 12 software (Stata, College Station, TX, USA) [50].

\section{Results \\ Characteristics and quality of the included studies}

Figure 1 presents a flowchart of the study inclusion process. We identified 218 studies from our literature search of the two databases. After removing 49 duplicates, we assessed 169 titles and abstracts, and excluded 154 records that did not meet the inclusion criteria. The full text of 15 citations was examined in detail. Nine studies fulfilled the inclusion criteria [26, 51-58], but two of them contained largely overlapping study populations $[26,53]$. In this case, the more recent study with the larger population was selected for inclusion to avoid duplication [53]. In total eight studies involving $3319 \mathrm{HL}$ patients were included in the meta-analysis [51-58]. Searching grey literatures, the reference lists of included studies and enquiring with academic experts on lymphoma did not identify further studies for inclusion. No unpublished relevant studies were identified. The conference abstracts and non-English literature that we did identify in our search were excluded because they did not contain enough information, had too short follow-up times, or were irrelevant.

Table 2 shows the characteristics of the included studies. All eight studies were published in English between 2012 and 2018 and all were retrospective cohort studies. All except one of these studies reported associations between LMR and OS [51-57]. Five reported on PFS $[51,52,54,55,58]$, and three reported on TTP $[51,52,56]$ and LSS [51-53], respectively. Only one study reported on EFS [57]. In all studies, HRs were estimated using Cox proportional hazards models for the associations between LMR and survival outcomes. A HR greater than one indicates a lower survival rate in patients with lower LMR. Seven studies were from the Western world and Israel [51, 52, 54-58], and one from Asia [53]. Median LMR among studies ranged from 2.1 to 3.3. In the study by Romano et al. [58], median LMR from healthy volunteers was described and it was 3.1 (range 0.6-4.0). LMR cut-off values and study sample sizes were not consistent across studies, LMR cut-off values ranged from 1.1 to 2.8 and sample sizes ranged from 101 to 1450. To determine the LMR cut-off values for analysis, studies used receiver operating characteristic curves and compared the sensitivity and specificity of the different cut-off values. Values having maximum joint sensitivity and specificity were selected. Other potential prognostic factors were investigated in some of the studies, including absolute monocyte count (AMC) [54], positron emission tomography (PET) [55], tumour associated macrophage (TAM) [57], and neutrophil-lymphocyte ratio (NLR) [58]. Some differences in the baseline characteristics such as stage and IPS in the LMR cut-off subgroups were noted in Porrata 2012b 


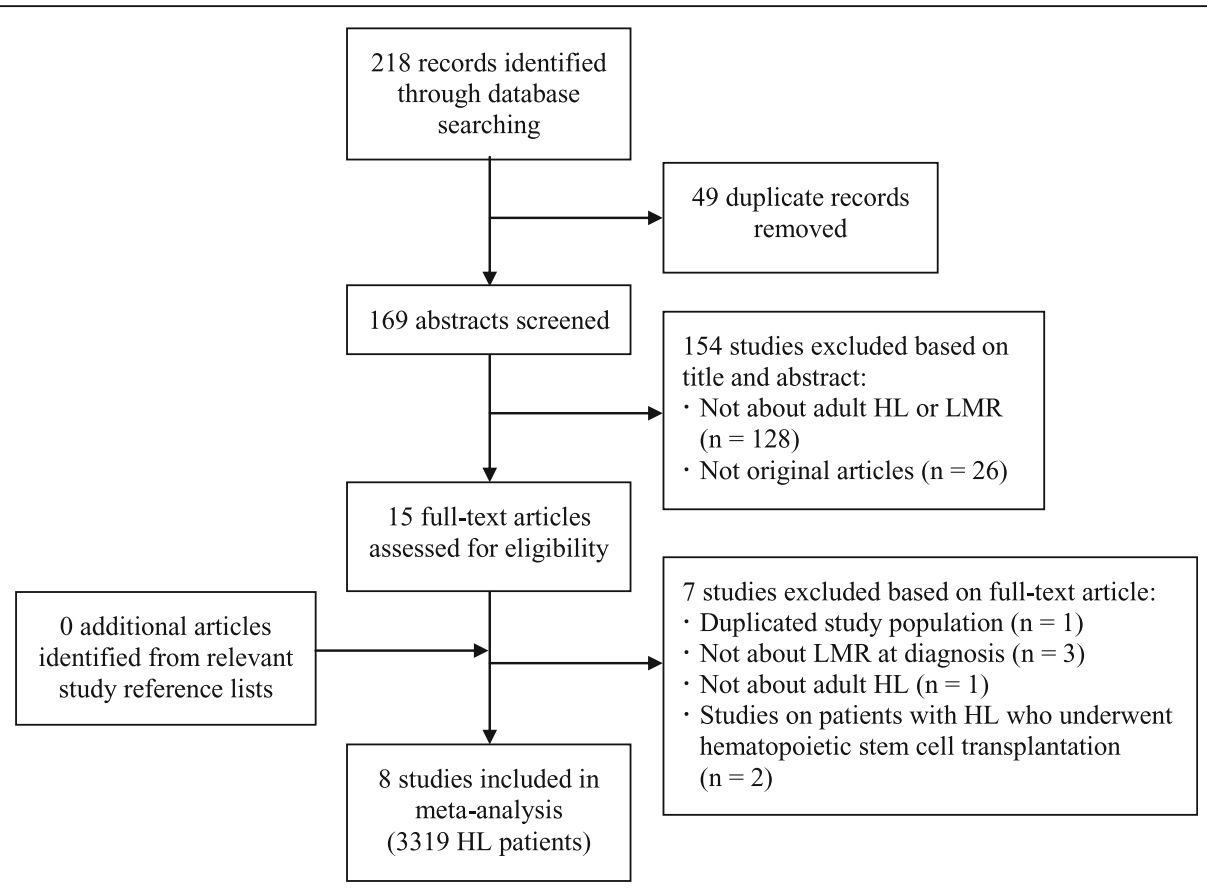

Fig. 1 Flow diagram of study selection

et al. [52], Koh et al. [53], Tadmor et al. [54], and Romano et al. [58]. However, these important confounders known to affect prognosis for HL have been adjusted for in the multivariable models.

Overall, we assessed three of the included studies as having low risk of bias and five of the studies as having moderate risk of bias. Details of the risk of bias assessment are presented in Additional file 2: Table S1. The primary issues related to participant recruitment, because the exclusion and inclusion criteria were not always clear, and to statistical analysis and reporting, due to insufficient detail provided about methodology used (e.g. the rationale for selection of control variables and the model building strategy).

\section{Meta-analysis}

Meta-analyses were conducted to investigate associations between LMR and OS and PFS, as these were the only survival outcomes for which four or more studies were identified.

\section{Association between LMR and overall survival}

In the meta-analysis, low LMR was associated with a significantly poorer OS, with a pooled HR of 2.66 (95\% CI 1.67, 4.26; $P=0.014 ; \mathrm{I}^{2}=62.5 \%$; Cochran $\mathrm{Q}$ test $P=$ 0.014) (Fig. 2).

We conducted subgroup analyses by sample size and LMR cut-off value. Four studies had a sample size over 300 [52-54, 56], and four studies had an LMR cut-off value greater than two [51, 53-55].
Studies with an LMR cut-off value greater than 2 had a pooled HR of 2.24 (95\% CI 1.18, 4.27, $P=0.014 ; \mathrm{I}^{2}=$ 58.2\%; Cochran $\mathrm{Q}$ test $P=0.066$ ) (Fig. 3), and studies with a sample size of 300 or more had a pooled HR of 2.76 (95\% CI 1.29, 5.91, $P=0.009 ; \mathrm{I}^{2}=78.1 \%$; Cochran Q test $P=0.003$ ) (Fig. 4).

\section{Association between LMR and progression-free survival}

Five studies reported on the correlation between LMR and PFS (see Fig. 5) [51, 52, 54, 55, 58]. All were non-Asian studies $[51,52,54,55,58]$, three had chosen an LMR cut-off value greater than $2[51,54,55]$, and two had a sample size larger than 300 [52, 54]. The pooled estimate showed that low LMR was strongly associated with poorer PFS, with HR 2.19 (95\% CI 1.46, 3.29, $P<0.001 ; \mathrm{I}^{2}=52.2 \%$; Cochran $\mathrm{Q}$ test $P=0.079$ ). Due to the lower number of analysable studies, subgroup analyses were not performed for PFS.

\section{Sensitivity analyses and publication bias}

We found that the results did not significantly change after omitting any of the included studies, demonstrating robustness of the results. The pooled HRs for OS ranged from 2.25 (95\% CI $1.47,3.43)$ to 3.12 (95\% CI 2.22 , 4.37). For PFS, the pooled HRs ranged from 1.86 (95\% CI $1.34,2.57)$ to 2.66 (95\% CI 1.82, 3.88) (Table 3).

We assessed publication bias visually using funnel plots (Fig. 6) and quantitatively using Egger's test. We observe asymmetry in the funnel plot, suggesting publication bias for OS, as studies appear to be missing in the 
Table 2 Characteristics of included studies assessing the LMR on prognosis in $\mathrm{HL}$

\begin{tabular}{|c|c|c|c|c|c|c|c|c|c|c|c|c|c|c|}
\hline Author (year) & $\begin{array}{l}\text { Setting and } \\
\text { design }\end{array}$ & $\begin{array}{c}\text { Sample } \\
\text { size }\end{array}$ & $\begin{array}{l}\text { Time } \\
\text { period }\end{array}$ & $\begin{array}{l}\text { Median } \\
\text { follow- } \\
\text { up in } \\
\text { years } \\
\text { (range) }\end{array}$ & $\begin{array}{l}\text { Median } \\
\text { age in } \\
\text { years } \\
\text { (range) }\end{array}$ & $\begin{array}{c}\text { Sex: } \\
\text { male }(\%) / \\
\text { female } \\
(\%)\end{array}$ & $\begin{array}{c}\text { Stage } \\
\text { III/IV } \\
(\%)\end{array}$ & $\begin{array}{l}\text { IPS } \\
\geq 3 \\
(\%)\end{array}$ & $\begin{array}{l}\text { Median } \\
\text { LMR } \\
\text { (range) }\end{array}$ & $\begin{array}{l}\text { LMR } \\
\text { cut- } \\
\text { off }\end{array}$ & $\begin{array}{c}\text { High } \\
\text { LMR (\%)/ } \\
\text { low LMR } \\
(\%)\end{array}$ & $\begin{array}{c}\text { Primary } \\
\text { treatment }\end{array}$ & $\begin{array}{c}\text { Survival } \\
\text { outcomes }\end{array}$ & $\begin{array}{l}\text { Confounders } \\
\text { adjusted for }\end{array}$ \\
\hline $\begin{array}{l}\text { Porrata et al. } \\
(2012 \mathrm{a})[51]\end{array}$ & $\begin{array}{l}\text { Single- } \\
\text { institution, } \\
\text { retrospective }\end{array}$ & 103 & $\begin{array}{l}1974- \\
2010\end{array}$ & $\begin{array}{c}8.9 \\
(0.3-31)\end{array}$ & $\begin{array}{c}44 \\
(18-82)\end{array}$ & $65.0 / 35.0$ & 17.5 & 15.0 & $\begin{array}{c}3.3 \\
(0.04- \\
90)\end{array}$ & 2.1 & $72.8 / 27.2$ & $\begin{array}{l}\text { Chemo, } \\
\text { RT or } \\
\text { both }\end{array}$ & $\begin{array}{l}\text { OS, PFS, } \\
\text { LSS, TTP }\end{array}$ & $\begin{array}{l}\text { age, sex, alb, Hb, } \\
\text { WBC, ALC, } \\
\text { AMC, stage, IPS }\end{array}$ \\
\hline $\begin{array}{l}\text { Porrata et al. } \\
(2012 b)[52]\end{array}$ & $\begin{array}{l}\text { Single- } \\
\text { institution, } \\
\text { retrospective }\end{array}$ & 476 & $\begin{array}{c}1974- \\
2000\end{array}$ & $\begin{array}{c}5.6 \\
(0.1- \\
33.7)\end{array}$ & $\begin{array}{c}36 \\
(18-83)\end{array}$ & $52.9 / 47.1$ & 57.1 & NR & NR & 1.1 & $70.4 / 29.6$ & $\begin{array}{l}\text { Chemo } \\
+/ \text { - RT }\end{array}$ & $\begin{array}{l}\text { OS, PFS, } \\
\text { LSS, TTP }\end{array}$ & $\begin{array}{c}\text { age, sex, alb, Hb, } \\
\text { WBC, ALC, } \\
\text { AMC, stage, IPS, } \\
\text { bulky disease, } \\
\text { treatment } \\
\text { modality }\end{array}$ \\
\hline $\begin{array}{l}\text { Koh et al. } \\
(2015)[53]\end{array}$ & $\begin{array}{l}\text { Single- } \\
\text { institution, } \\
\text { retrospective }\end{array}$ & 351 & $\begin{array}{l}1989- \\
2012\end{array}$ & $\begin{array}{c}4.9 \\
(0.0- \\
20.4)\end{array}$ & $\begin{array}{c}32 \\
(4-84)\end{array}$ & $61.3 / 38.7$ & 50.4 & $33.9^{\mathrm{a}}$ & $\begin{array}{c}3.0 \\
(0.37- \\
29.5)\end{array}$ & 2.8 & $54.5 / 45.5$ & $\begin{array}{l}\text { Chemo } \\
+/- \text { RT }\end{array}$ & OS, LSS & $\begin{array}{l}\text { B symptoms, } \\
\text { Epstain-Barr } \\
\text { virus, IPS }\end{array}$ \\
\hline $\begin{array}{l}\text { Tadmor et al. } \\
(2015)[54]\end{array}$ & $\begin{array}{l}\text { multi-center } \\
\text { retrospective }\end{array}$ & 1450 & $\begin{array}{l}1988- \\
2007\end{array}$ & $\begin{array}{l}7.3 \\
(0.1- \\
20.3)\end{array}$ & $\begin{array}{c}33 \\
(17-72)\end{array}$ & $50.2 / 49.8$ & NR & $27.0^{\mathrm{a}}$ & $\begin{array}{c}2.8 \\
(0.7- \\
17)^{\mathrm{b}}\end{array}$ & 2.1 & $66.0 / 34.0$ & $\begin{array}{l}\text { Chemo } \\
+/ \text { - RT }\end{array}$ & OS, PFS & $\begin{array}{c}\text { histological } \\
\text { subtypes, IPS }\end{array}$ \\
\hline $\begin{array}{l}\text { Simon et al. } \\
(2016)[55]\end{array}$ & $\begin{array}{l}\text { Single- } \\
\text { institution, } \\
\text { retrospective }\end{array}$ & 121 & $\begin{array}{l}2007- \\
2013\end{array}$ & $\begin{array}{l}4.0^{\mathrm{c}} \\
(0.9- \\
6.7)\end{array}$ & $\begin{array}{c}36.7 \\
(17-79)\end{array}$ & $49.6 / 50.4$ & 46.3 & NR & NR & 2.11 & NR & $\begin{array}{l}\text { Chemo } \\
+/ \text { - RT }\end{array}$ & OS, PFS & $\begin{array}{c}\text { age, sex, stage, B } \\
\text { symptoms, bulky } \\
\text { disease, treatment } \\
\text { modality }\end{array}$ \\
\hline $\begin{array}{l}\text { Vassilakopoulos } \\
\text { et al. (2016)[56] }\end{array}$ & $\begin{array}{l}\text { Multi-center, } \\
\text { retrospective }\end{array}$ & 537 & $\mathrm{NR}^{\mathrm{d}}$ & $\begin{array}{c}3.4 \\
\text { (NR) }\end{array}$ & $\begin{array}{c}32 \\
(15-87)\end{array}$ & $52.7 / 47.3$ & 35.0 & 32.0 & $\begin{array}{c}2.24 \\
(0.44- \\
20.50)\end{array}$ & 1.1 & $88.8 / 11.2$ & $\begin{array}{l}\text { Chemo } \\
+/ \text { - RT }\end{array}$ & OS, TTP & $\begin{array}{c}\text { age, sex, stage, B } \\
\text { symptoms, } \\
\text { number of } \\
\text { involved sites, } \\
\text { iliac or inguinal } \\
\text { involvement, } \\
\text { anaemia, ESR, } \\
\text { AMC, IPS }\end{array}$ \\
\hline $\begin{array}{l}\text { Jakovic et al. } \\
\text { (2016)[57] }\end{array}$ & $\begin{array}{l}\text { Single- } \\
\text { institution, } \\
\text { retrospective }\end{array}$ & 101 & $\begin{array}{l}1997- \\
2007\end{array}$ & $\begin{array}{c}8.6 \\
(0.2-16)\end{array}$ & $\begin{array}{c}\text { NR } \\
(16-80)\end{array}$ & $53.5 / 46.5$ & 88.1 & 53.5 & NR & 2.0 & $59.4 / 40.6$ & $\begin{array}{l}\text { Chemo } \\
+/ \text { - RT }\end{array}$ & OS, EFS & $\begin{array}{l}\text { CD68+ tumour } \\
\text { associated } \\
\text { macrophage, IPS. }\end{array}$ \\
\hline$(2018)[58]$ & $\begin{array}{l}\text { Single- } \\
\text { institution, } \\
\text { retrospective }\end{array}$ & 180 & $\begin{array}{l}2006- \\
2012\end{array}$ & $\begin{array}{c}5.7 \\
(0.5- \\
7.0)\end{array}$ & $\begin{array}{c}31.7 \\
(15-77)\end{array}$ & $50.0 / 50.0$ & 66.1 & $71^{e}$ & $\begin{array}{c}2.1 \\
(0.2- \\
8.4)^{\mathrm{f}}\end{array}$ & 2 & $54.4 / 45.6$ & $\begin{array}{l}\text { Chemo } \\
\text { +/- RT }\end{array}$ & PFS & $\begin{array}{l}\text { ANC, ALC, Hb, } \\
\text { NLR, interim PET } \\
\text { status, IPS }\end{array}$ \\
\hline
\end{tabular}

Studies with a low overall risk of bias are shaded in grey

${ }^{a}$ Data were obtained by contacting the author

${ }^{b} 2.5$ th to 97.5 th percentile were stated instead of range

cMean follow-up in years (range)

${ }^{\mathrm{d}}$ The time period and range of follow-up in years were not reported

e IPS $\geq 2$ (\%)

this study also provided median (range) of LMR of healthy control: $3.1(0.6-4.0)$

Abbreviations: Alb albumin, ALC absolute lymphocyte count, AMC absolute monocyte count, ANC absolute neutrophil count, chemo chemotherapy, EFS event-free survival, $H b$ haemoglobin, $H L$ Hodgkin's lymphoma, $H R$ hazard ratios, IPS international prognostic score, LMR lymphocyte-monocyte ratio, $L S S$ lymphoma-specific survival, NLR neutrophil-lymphocyte ratio, NR not reported, OS overall survival, PET positron emission tomography, PFS progression-free survival, $R T$ radiotherapy, TTP time-to-progression, WBC white blood cell count

bottom left corner of the funnel plot. The null hypothesis for Egger's test is that symmetry exists in the funnel plot. The $P$-values from the Egger test for OS and PFS are 0.022 and 0.117 respectively. There is therefore evidence to reject the null hypothesis at the $10 \%$ significance level for OS.

\section{Discussion}

LMR may reflect the interplay between the host immunity and tumour microenvironment. The strong association identified through the meta-analyses between baseline LMR and survival outcomes indicates that LMR could be a good prognostic biomarker.

Low LMR at diagnosis may be related to more aggressive disease nature or to poorer tolerance to anti-cancer treatment. Low peripheral blood ALC and/or high AMC can cause low LMR. Lymphopenia, defined in IPS as < $0.6 \times 10^{9} / \mathrm{L}$ or $<8 \%$ of total white cell, is a known prognostic factor for HL $[18,31]$.
This is compatible with our results because low ALC can lead to low LMR if the AMC is unchanged, since LMR is a ratio. Peripheral blood ALC is thought to be a surrogate of the host's immunity status. On the other hand, the role of monocytes is different. One study showed that the peripheral blood AMC is positively associated with TAM content in lesional tissue samples, [26]. This is consistent with the evidence that TAMs originate from blood monocytes. TAM is important in cancer cell survival and proliferation and its quantity has been shown to be associated with poorer outcomes in a number of cancers [24]. Monocyte chemoattractant protein (MCP-1) belongs to the cytokine superfamily, and its binding with receptors triggers downstream signals that regulate macrophage adhesion, and recruit TAMs. MCP-1 has been associated with tumour growth and disease progression in several kinds of cancer [59]. Furthermore, a subpopulation of immune cells called monocytic myeloid derived suppressor cells (MDSCs) has been identified in marrow and peripheral blood. Their 


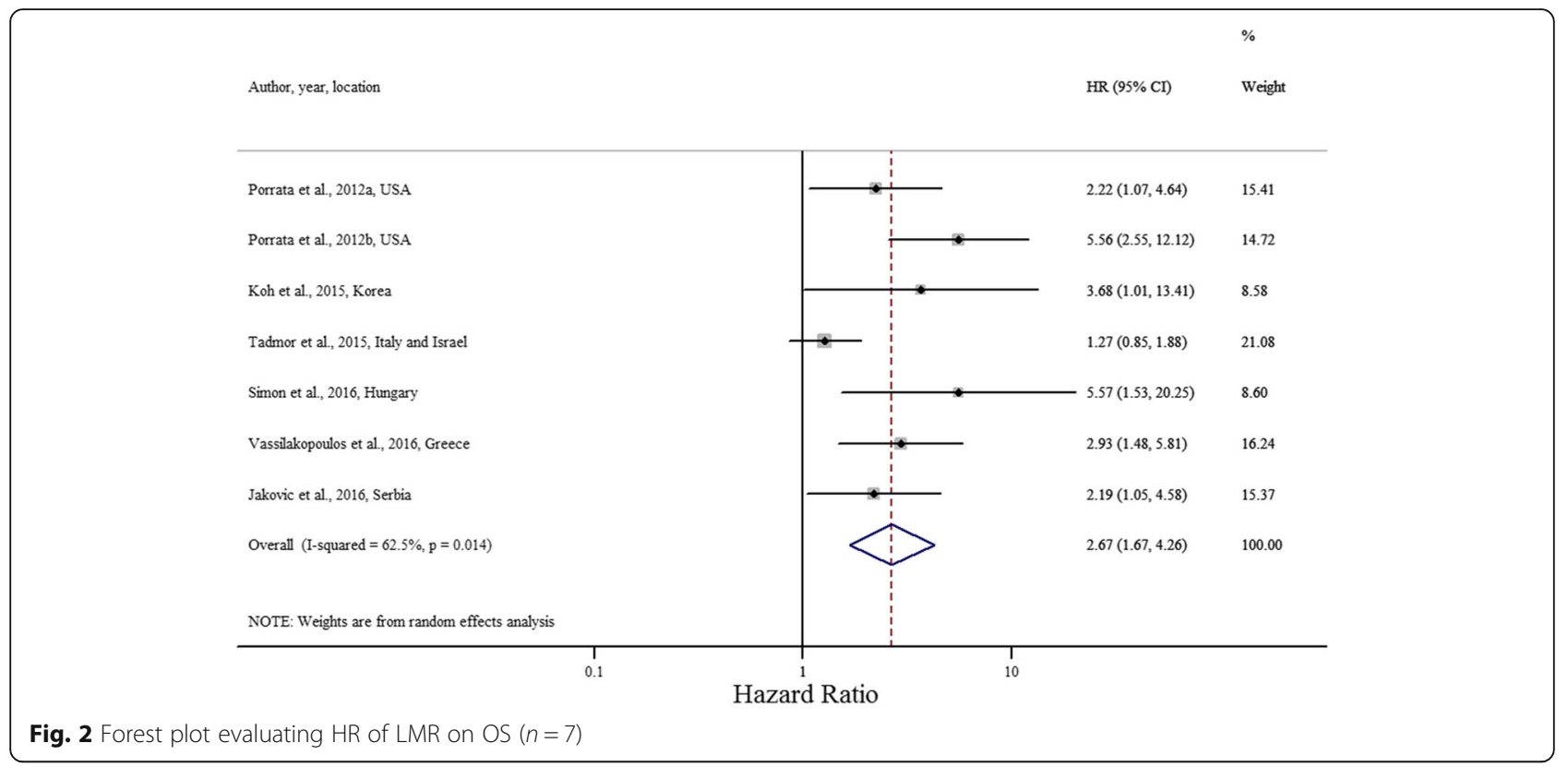

accumulation has been associated with cancer related inflammation and immunosuppression. MDSCs are also correlated with TAMs, and an increased amount of MDSCs confers a poorer prognosis in many cancer types including HL [60-62]. The available evidence thus demonstrates the prognostic role of non-malignant immune cells, and the possible utility of these in determining accurate prognoses.

This review has several strengths. The median follow-up periods in the included studies of patients with a well-defined disease entity were likely adequate (range 3.4-8.9 years), since most of the relapses of HL typically occur within the first 3 years [63]. LMR as a prognostic factor is biologically sound, and is determined by a simple, widely available blood test. In the subgroup analyses stratified by sample size and cut-off value, the prognostic value of LMR remained significant.

We do, however, need to be cautious in interpreting our results as all included studies were retrospective observational studies and it is possible that not all sources

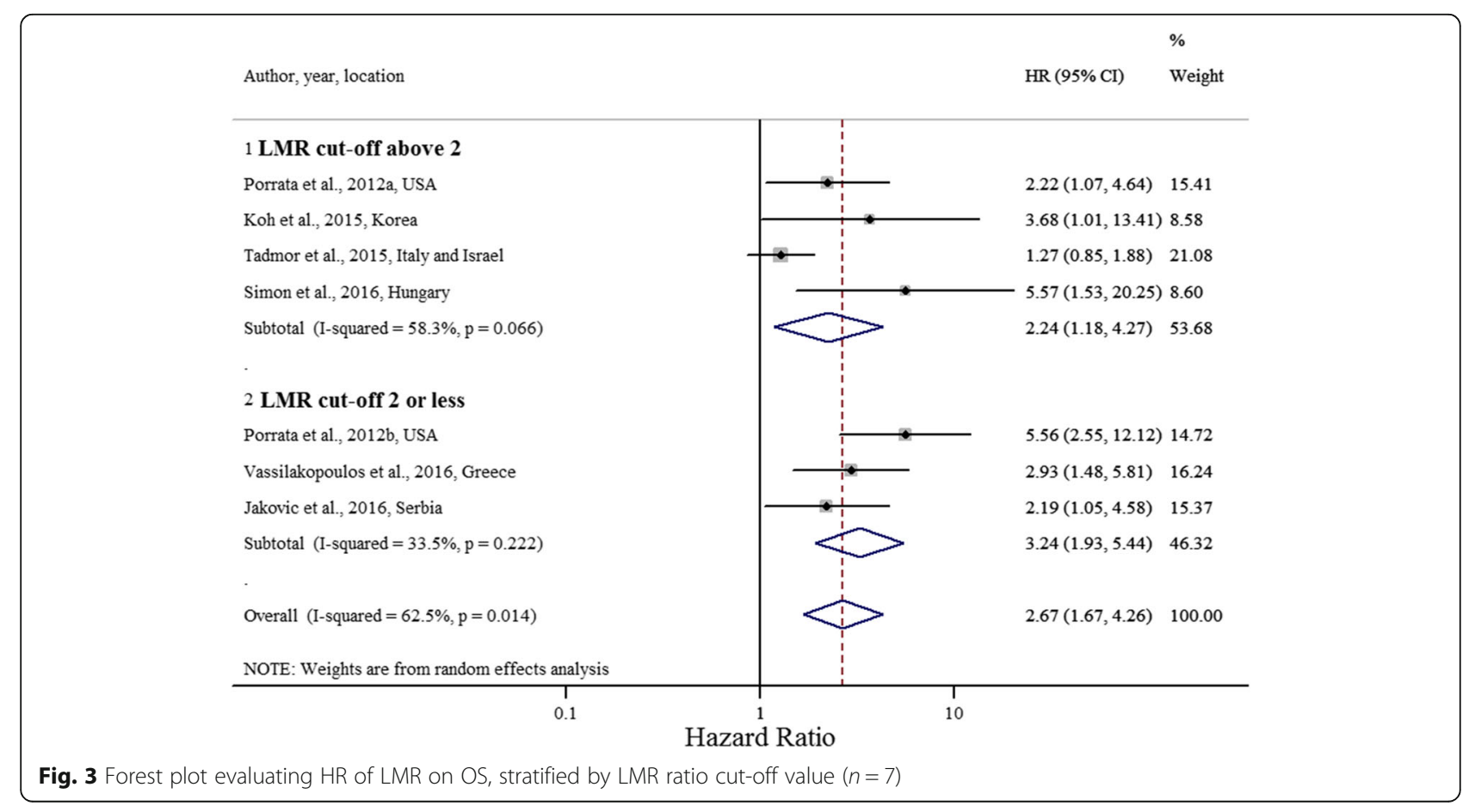




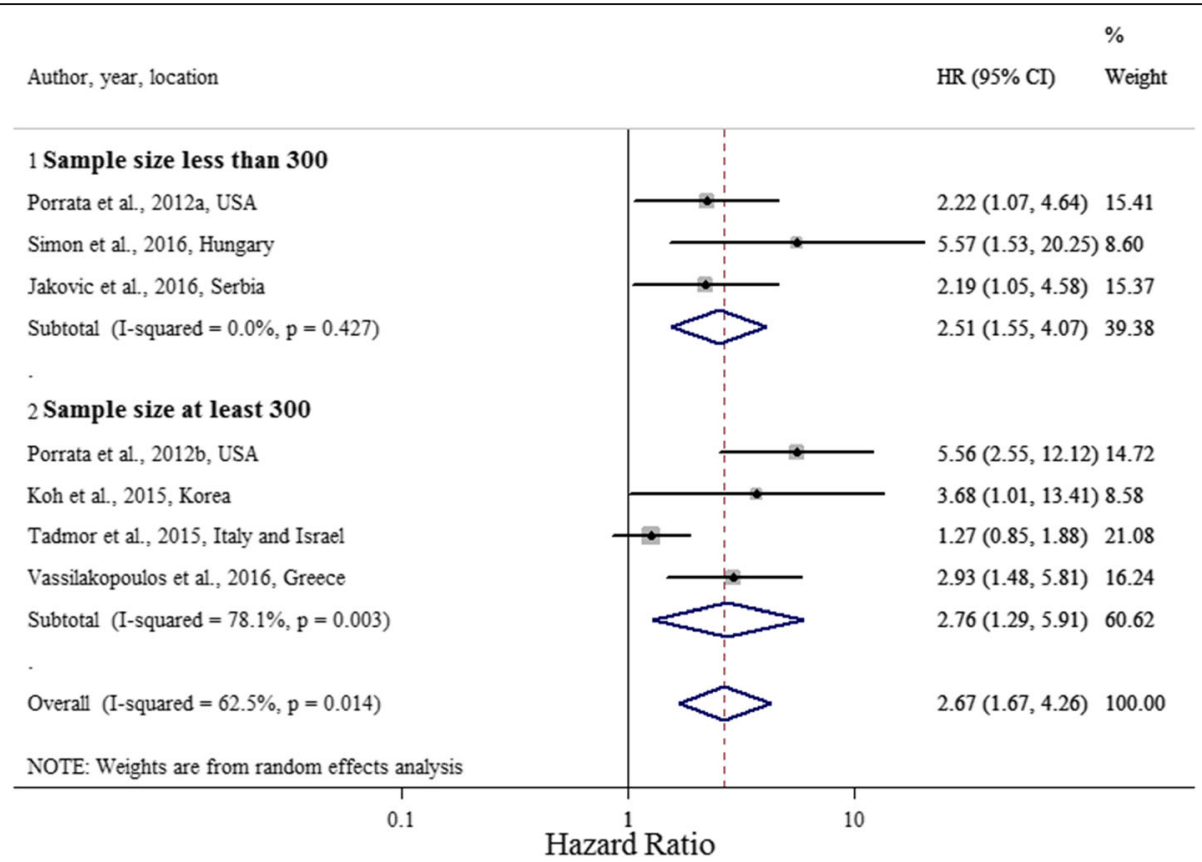

Fig. 4 Forest plot evaluating HR of LMR on OS, stratified by study sample size $(n=7)$

of heterogeneity have been adjusted for. Each included study had adjusted for some different covariables, and was conducted in different countries (one from Asia and seven from the Western world, including Israel). The differing ethnic groups and patient characteristics could be one reason for the variable effect sizes found. The optimal LMR cut-off values determined also varied across studies, possibly related to sample variability and differences in baseline patient characteristics. For example, a decrease in lymphocyte counts has been observed more frequently in the elderly [64]. The different treatment regimens (types and doses of chemotherapy agent) may also interact with other factors, such as age and performance status, resulting in variable survival outcomes.

An important limitation of this meta-analysis is that the number of included studies is modest, only eight. This limited the kinds of subgroup analyses we could perform because the number of available studies in some subgroups was low. For instance, subgroup analysis by study region could not be conducted because only one Asian study was available. This could have been useful because although ethnicity was not detailed in the

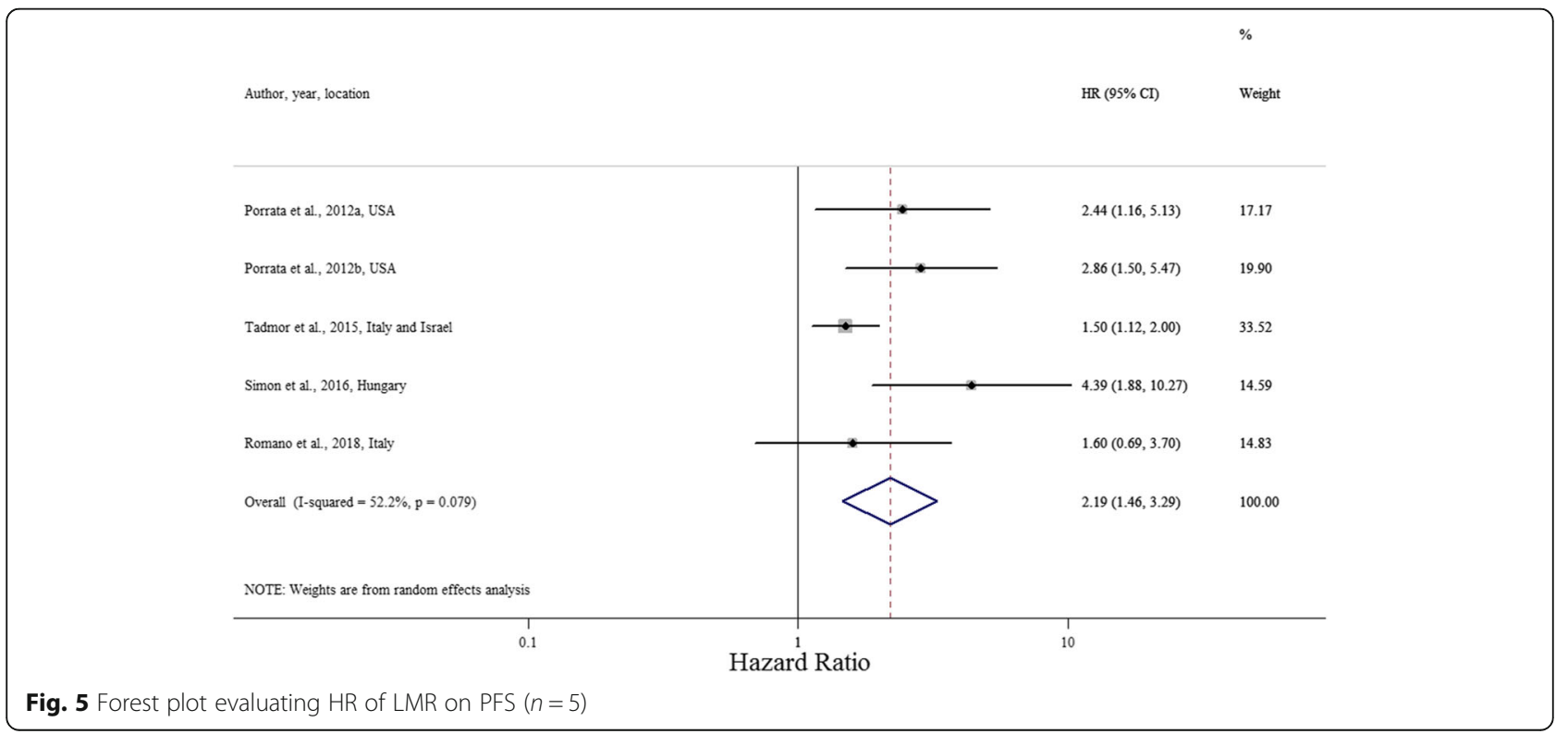


Table 3 Sensitivity analysis by sequential omission of each individual study

\begin{tabular}{lll}
\hline \multicolumn{3}{l}{ Meta-analysis estimates, given the named study is omitted } \\
\hline Study omitted & $\begin{array}{l}\text { Hazard ratio for overall } \\
\text { survival }(95 \% \text { Cl) }\end{array}$ & $\begin{array}{l}\text { Hazard ratio for } \\
\text { progression-free } \\
\text { survival }(95 \% \text { Cl) }\end{array}$ \\
\hline Porrata et al. (2012a) [51] & $2.82(1.61,4.93)$ & $2.18(1.33,3.59)$ \\
Porrata et al. (2012b) [52] & $2.25(1.47,3.43)$ & $2.06(1.29,3.29)$ \\
Koh et al. (2015) [53] & $2.60(1.57,4.31)$ & - \\
Tadmor et al. (2015) [54] & $3.12(2.22,4.37)$ & $2.66(1.82,3.88)$ \\
Simon et al. (2016) [55] & $2.48(1.53,4.01)$ & $1.86(1.34,2.57)$ \\
Vassilakopoulos et al. (2016) [56] & $2.66(1.53,4.63)$ & - \\
Jakovic et al. (2016) [57] & $2.82(1.61,4.94)$ & - \\
Romano et al. (2018) [58] & - & $2.37(1.45,3.90)$ \\
\hline
\end{tabular}

studies, study regions could be surrogates of ethnic groups. It would have been useful to know whether ethnic (regional) differences modify the results, and if the findings can be applied to different ethnic groups.

Importantly, we do find evidence of publication bias in reporting of OS. Publication bias arises when the publication of findings is influenced by the nature and direction of the study results [65]. Although tests for publication bias are optimal only if the number of studies included in a meta-analysis is at least 10 [42], the interpretation of the effect estimate needs caution, as studies seem to be missing in the bottom left-hand side of the funnel plot (Fig. 6). Such studies would probably be trials with large standard errors and small sample sizes, with an overall survival for high LMR lower than

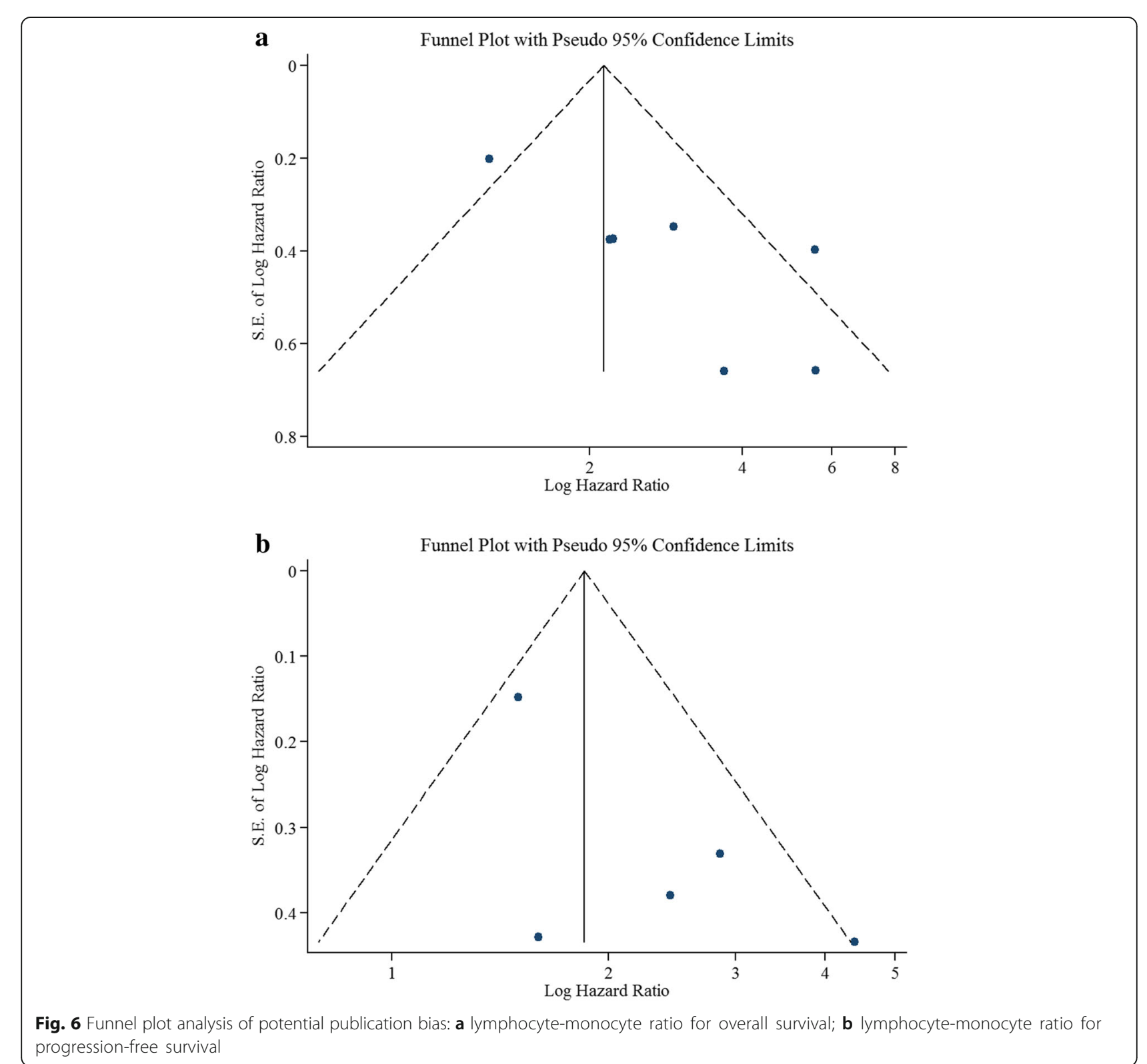


that for low LMR. However, it is only an assumption that these studies were ever undertaken [66]. Asymmetry in a funnel plot can also result from poor methodological design in the identified studies, because poor methodological design typically results in the estimated effect size being spuriously magnified.

Potential problems with prognostic studies are manifold [67]. The most relevant ones for our study are: a) primary outcomes might not always be well defined, and b) there is no methodological and reporting standard, so that important information may be omitted and the importance of conclusions may be artificially inflated.

When assessing risk of bias and study quality we did find that five studies had a moderate risk of bias. Although each of the included studies had different risks of bias, their respective estimated HRs for OS and PFS were, however, similar at around $2-3$. In the sensitivity analysis where we sequentially omitted each study, the results were largely stable, and no significant difference between studies of low risk and moderate risk was found.

Prior to conducting the pooled analysis, we assumed that effect sizes of the association between LMR and survival time may differ according to the methodological quality of the studies, so we decided to use a random-effects model for analysis. Furthermore, measures were taken to minimise the impact of other sources of reporting biases: we screened non-English papers and grey literature, including abstracts of studies presented at conferences and published in conference proceedings, and academic experts on lymphoma were consulted to identify further data. However, given the strong association between LMR and OS and PFS, respectively, and the observation that there was no significant change in the magnitude and direction of the pooled HRs in subgroup analyses and sensitivity analyses, the findings suggest that baseline LMR could be a significant prognostic marker in HL.

\section{Implications}

Determination of protein (MCP-1) and immune cell subpopulations (TAM and MDSC) is costly, not available in routine daily clinical practice, and can be hard to interpret. On the contrary, measurement of LMR is easily performed. LMR is an inexpensive biomarker that can be determined by use of complete blood count machine, which is widely available worldwide. Data suggest that many aspects of standard care in modern medicine are lacking in developing countries and their treatment outcomes appear inferior in HL [68]. Initial imaging investigations may comprise chest $\mathrm{X}$-rays and ultrasonography of the abdomen, which fall short of current standards [69]. Cell count ratios can be a simple complement that offers additional information in such situations.
Future directions for research include finding a unified cut-off value for HL, exploring the specific white cell subtypes (like B-lymphocyte and T-lymphocytes) and the value of their cell ratios in prognostic prediction, and investigating the combination of cell count ratios with established prognostic factors. The combination of different prognostic factors might be able to discriminate risks of disease progression and survival better. Finally, a prospective validation study should be conducted to confirm the clinical value of LMR and allow us to implement it in routine use.

\section{Conclusion}

Low LMR at diagnosis is associated with poor OS and PFS. LMR therefore has the potential to be a practical biomarker that predicts survival outcomes in adult HL. A more accurate prediction in prognosis could allow clinicians to better tailor the treatment regimens according to individual risks. The test is inexpensive and easy to perform in outpatient or inpatient settings. Future prospective studies are needed to confirm its exact role in the disease management of $\mathrm{HL}$, and the possibility of combining it with other established prognostic factors.

\section{Additional files}

Additional file 1: Appendix S1. Electronic databases search strategy (DOCX $13 \mathrm{~kb}$ )

Additional file 2: Table S1. Risk of bias assessment of included studies using the Quality in Prognostic Studies tool. The six domains represent important issues to consider when evaluating the overall validity and bias in studies of prognostic factors. Some domains may not be relevant to the specific study. (DOCX $23 \mathrm{~kb}$ )

\section{Abbreviations}

ALC: Absolute lymphocyte count; AMC: Absolute monocyte count; Cl: Confidence interval; EFS: Event free survival; EORTC: European Organisation for Research and Treatment of Cancer; GHSG: German Hodgkin Study Group; HL: Hodgkin's Lymphoma; HR: Hazard ratio; IPS: International prognostic score; LMR: Lymphocyte monocyte ratio; LSS: Lymphocyte specific survival; MCP-1: Monocyte chemoattractant protein-1; MDSCs: Monocytic myeloid derived suppressor cells; NCIC: National Cancer Institute of Canada; NLPHL: Nodular lymphocyte predominant Hodgkin's Lymphoma; NLR: Neutrophil-lymphocyte ratio; NR: Not reported; OS: Overall survival; PET: Positron emission tomography; PFS: Progression-free survival; PRISMA: Preferred Reporting Items for Systematic Reviews and Meta-Analyses; QUIPS: Quality In Prognosis Studies; TAM: Tumour associated macrophage; TTP: Time to progression

\section{Acknowledgments}

The authors thank the study participants in each of the individual studies for their involvement.

Funding

None to declare.

Availability of data and materials

Meta-analysis is a secondary analysis, which the data are all fully available without restriction, and all the material can be found in the included original studies. 


\section{Authors' contributions}

SFL developed the concept and design of the study as a thesis for MSC Epidemiology in University of London. SFL analysed the data with DS guidance. SFL, TYN and DS wrote the manuscript. Authors interpreted the data, drafted and revised the manuscript critically, and approved the final version of the manuscript. SFL is the guarantor of the paper.

\section{Ethics approval and consent to participate}

All analyses were based on previous published studies, thus no ethical approval and patient consent are required.

\section{Consent for publication}

Not applicable.

\section{Competing interests}

The authors declare that they have no competing interests.

\section{Publisher's Note}

Springer Nature remains neutral with regard to jurisdictional claims in published maps and institutional affiliations.

\section{Author details}

${ }^{1}$ Department of Clinical Oncology, Tuen Mun Hospital, New Territory West Cluster, Hospital Authority, Tuen Mun, Hong Kong. ${ }^{2}$ Health Economics Unit, Department of Clinical Science (Malmö), Lund University, Lund, Sweden. ${ }^{3}$ Department of Economics, School of Economics and Management, Lund University, Lund, Sweden. ${ }^{4}$ London School of Hygiene and Tropical Medicine, London, UK.

\section{Received: 27 May 2018 Accepted: 28 March 2019}

\section{Published online: 11 April 2019}

\section{References}

1. Smith A, Crouch S, Lax S, Li J, Painter D, Howell D, Patmore R, Jack A, Roman E. Lymphoma incidence, survival and prevalence 2004-2014: sub-type analyses from the UK/'s Haematological malignancy research network. Br J Cancer. 2015:112:1575-84.

2. Mani H, Jaffe ES. Hodgkin lymphoma: an update on its biology with new insights into classification. Clin Lymphoma Myeloma. 2009:9:206-16.

3. Eichenauer DA, Engert $A$, André $M$, Federico $M$, Illidge $T$, Hutchings $M$, Ladetto M. Hodgkin's lymphoma: ESMO clinical practice guidelines for diagnosis, treatment and follow-upt. Ann Oncol. 2014;25:iii70-5.

4. Engert A, Ballova V, Haverkamp H, Pfistner B, Josting A, Duhmke E, MullerHermelink K, Diehl V. Hodgkin's lymphoma in elderly patients: a comprehensive retrospective analysis from the German Hodgkin's study group. J Clin Oncol. 2005;23:5052-60.

5. Levis A, Anselmo AP, Ambrosetti A, Adamo F, Bertini M, Cavalieri E, et al. VEPEMB in elderly Hodgkin's lymphoma patients. Results from an Intergruppo Italiano Linfomi (IIL) study. Ann Oncol. 2004;15:123-8.

6. Stark GL, Wood KM, Jack F, Angus B, Proctor SJ, Taylor PR. Northern region lymphoma G: Hodgkin's disease in the elderly: a population-based study. Br J Haematol. 2002;1 19:432-40.

7. Ries LAG KC, Hankey BF, Miller BA, Clegg L, Edwards BK (eds). SEER Cancer statistics review, 1973-1996, National Cancer Institute. Bethesda, MD, 1999.

8. Engert A, Horning SJ. Hodgkin lymphoma: a comprehensive update on diagnostics and clinics. Berlin Heidelberg: Springer; 2010.

9. American Cancer Society. Cancer Statistics Center Analysis Tool. 2018. https://cancerstatisticscenter.cancer.org/\#!/data-analysis/IncRate. Accessed 30 Apr 2018

10. Cancer Research UK. Hodgkin lymphoma statistics 2018 http://www.cancer researchuk.org/health-professional/cancer-statistics/statistics-by-cancer-type/ hodgkin-lymphoma. Accessed 30 Apr 2018.

11. Diehl V. Hematology: are macrophages the bad guys in Hodgkin lymphoma? Nat Rev Clin Oncol. 2010;7:301-2.

12. Bröckelmann PJ, Angelopoulou MK, Vassilakopoulos TP. Prognostic factors in Hodgkin lymphoma. Semin Hematol. 2016;53:155-64.

13. Ng AK, Mauch PM. Late effects of Hodgkin's disease and its treatment Cancer J. 2009;15:164-8

14. Schmitz N, Pfistner B, Sextro M, Sieber M, Carella AM, Haenel M, et al. Aggressive conventional chemotherapy compared with high-dose chemotherapy with autologous haemopoietic stem-cell transplantation for relapsed chemosensitive Hodgkin's disease: a randomised trial. Lancet. 2002;359:2065-71.

15. Straus DJ. Long-term survivorship at a Price: late-term, therapy-associated toxicities in the adult Hodgkin lymphoma patient. Therapeutic Advances in Hematology. 2011;2:111-9.

16. van Leeuwen $\mathrm{FE}, \mathrm{Ng} \mathrm{AK}$. Long-term risk of second malignancy and cardiovascular disease after Hodgkin lymphoma treatment. Hematology Am Soc Hematol Educ Program. 2016;2016:323-30.

17. Engert A, Plutschow A, Eich HT, Lohri A, Dorken B, Borchmann P, et al. Reduced treatment intensity in patients with early-stage Hodgkin's lymphoma. N Engl J Med. 2010;363:640-52.

18. Hasenclever D, Diehl V. A prognostic score for advanced Hodgkin's disease. International prognostic factors project on advanced Hodgkin's disease. N Engl J Med. 1998;339:1506-14.

19. Biasoli I, Stamatoullas A, Meignin V, Delmer A, Reman O, Morschhauser F, Coiffier B, Bosly A, Divine M, Brice P. Nodular, lymphocyte-predominant Hodgkin lymphoma: a long-term study and analysis of transformation to diffuse large B-cell lymphoma in a cohort of 164 patients from the adult lymphoma study group. Cancer. 2010;116:631-9.

20. Diehl V, Sextro M, Franklin J, Hansmann ML, Harris N, Jaffe E, et al. Clinical presentation, course, and prognostic factors in lymphocyte-predominant Hodgkin's disease and lymphocyte-rich classical Hodgkin's disease: report from the European task force on lymphoma project on lymphocytepredominant Hodgkin's disease. J Clin Oncol. 1999;17:776-83.

21. Bose S, Ganesan C, Pant M, Lai C, Tabbara IA. Lymphocyte-predominant Hodgkin disease: a comprehensive overview. Am J Clin Oncol. 2013;36:91-6.

22. Ferme C, Eghbali H, Meerwaldt JH, Rieux C, Bosq J, Berger F, et al. Chemotherapy plus involved-field radiation in early-stage Hodgkin's disease. N Engl J Med. 2007; 357:1916-27.

23. Meyer RM, Gospodarowicz MK, Connors JM, Pearcey RG, Wells WA, Winter $J \mathrm{~N}$, et al. ABVD alone versus radiation-based therapy in limited-stage Hodgkin's lymphoma. N Engl J Med. 2012;366:399-408.

24. Steidl C, Lee T, Shah SP, Farinha P, Han G, Nayar T, et al. Tumor-associated macrophages and survival in classic Hodgkin's lymphoma. N Engl J Med. 2010;362:875-85.

25. Ribatti D, Nico B, Crivellato E, Vacca A. Macrophages and tumor angiogenesis. Leukemia. 2007;21:2085-9.

26. Koh YW, Kang HJ, Park C, Yoon DH, Kim S, Suh C, Go H, Kim JE, Kim CW Huh J. The ratio of the absolute lymphocyte count to the absolute monocyte count is associated with prognosis in Hodgkin's lymphoma: correlation with tumor-associated macrophages. Oncologist. 2012;17: $871-80$.

27. Shivakumar L, Ansell S. Targeting B-lymphocyte stimulator/B-cell activating factor and a proliferation-inducing ligand in hematologic malignancies. Clin Lymphoma Myeloma. 2006;7:106-8.

28. Lamagna C, Aurrand-Lions M, Imhof BA. Dual role of macrophages in tumor growth and angiogenesis. J Leukoc Biol. 2006;80:705-13.

29. Corzo CA, Condamine T, Lu L, Cotter MJ, Youn Jl, Cheng P, et al. HIF-1alpha regulates function and differentiation of myeloid-derived suppressor cells in the tumor microenvironment. J Exp Med. 2010;207:2439-53.

30. Doedens AL, Stockmann C, Rubinstein MP, Liao D, Zhang N, DeNardo DG, Coussens LM, Karin M, Goldrath AW, Johnson RS. Macrophage expression of hypoxia-inducible factor-1 alpha suppresses T-cell function and promotes tumor progression. Cancer Res. 2010;70:7465-75.

31. Mocikova $\mathrm{H}$. Prognostic significance of absolute lymphocyte count and lymphocyte subsets in lymphomas. Prague Med Rep. 2010;111:5-11.

32. Rassidakis GZ, Medeiros $\amalg$, Vassilakopoulos TP, Viviani S, Bonfante V, Nadali $\mathrm{G}$, et al. BCL-2 expression in Hodgkin and reed-Sternberg cells of classical Hodgkin disease predicts a poorer prognosis in patients treated with ABVD or equivalent regimens. Blood. 2002;100:3935-41.

33. Kelley TW, Pohlman B, Elson P, Hsi ED. The ratio of FOXP3+ regulatory $T$ cells to granzyme $B+$ cytotoxic T/NK cells predicts prognosis in classical Hodgkin lymphoma and is independent of bcl-2 and MAL expression. Am J Clin Pathol. 2007;128:958-65.

34. Belotti A, Doni E, Bolis S, Rossini F, Casaroli I, Pezzatti S, Pogliani EM, Pioltelli PE. Peripheral blood lymphocyte/monocyte ratio predicts outcome in follicular lymphoma and in diffuse large B-cell lymphoma patients in the rituximab era. Clin Lymphoma Myeloma Leuk. 2015;15:208-13.

35. Markovic O, Popovic L, Marisavljevic D, Jovanovic D, Filipovic B, Stanisavljevic D, et al. Comparison of prognostic impact of absolute lymphocyte count, absolute monocyte count, absolute lymphocyte count/absolute monocyte 
count prognostic score and ratio in patients with diffuse large B cell lymphoma. Eur J Intern Med. 2014;25:296-302.

36. Li N, Zhang L, Song HL, Zhang J, Weng HW, Zou LQ. Prognostic impact of absolute lymphocyte count/absolute monocyte count ratio and prognostic score in patients with nasal-type, extranodal natural killer/T-cell lymphoma. Tumour Biol. 2017:39:1010428317705503.

37. Romano A, Vetro C, Donnarumma D, Forte S, Ippolito M, Di Raimondo F. Early interim 2-(1)fluoro-2-deoxy-D-glucose positron emission tomography is prognostically superior to peripheral blood lymphocyte/monocyte ratio at diagnosis in classical Hodgkin's lymphoma. Haematologica. 2012;97:e21-3.

38. Gu L, Li H, Chen L, Ma X, Li X, Gao Y, Zhang Y, Xie Y, Zhang X. Prognostic role of lymphocyte to monocyte ratio for patients with cancer: evidence from a systematic review and meta-analysis. Oncotarget. 2016;7:31926-42.

39. Cheson BD, Pfistner B, Juweid ME, Gascoyne RD, Specht L, Horning SJ, et al. Revised response criteria for malignant lymphoma. J Clin Oncol. 2007;25: 579-86

40. Liberati A, Altman DG, Tetzlaff J, Mulrow C, Gotzsche PC, loannidis JP, Clarke M, Devereaux PJ, Kleijnen J, Moher D. The PRISMA statement for reporting systematic reviews and meta-analyses of studies that evaluate health care interventions: explanation and elaboration. PLoS Med. 2009;6:e1000100.

41. Stroup DF, Berlin JA, Morton SC, Olkin I, Williamson GD, Rennie D, Moher D, Becker BJ, Sipe TA, Thacker SB. Meta-analysis of observational studies in epidemiology: a proposal for reporting. Meta-analysis of observational studies in epidemiology (MOOSE) group. Jama. 2000;283:2008-12.

42. Higgins JPT GSe: Cochrane handbook for systematic reviews of interventions version 5.1.0 [updated march 2011]. The Cochrane Collaboration, 2011. Available from http://handbook-5-1.cochrane.org/. Accessed 30 Apr 2018.

43. Hayden JA, van der Windt DA, Cartwright JL, Cote P, Bombardier C. Assessing bias in studies of prognostic factors. Ann Intern Med. 2013; 158:280-6.

44. Higgins JP, Thompson SG. Quantifying heterogeneity in a meta-analysis. Stat Med. 2002;21:1539-58.

45. Higgins JP, Thompson SG, Deeks JJ, Altman DG. Measuring inconsistency in meta-analyses. BMJ. 2003;327:557-60.

46. DerSimonian R, Laird N. Meta-analysis in clinical trials. Control Clin Trials. 1986;7:177-88

47. Easterbrook PJ, Berlin JA, Gopalan R, Matthews DR. Publication bias in clinical research. Lancet. 1991;337:867-72.

48. Egger M, Davey Smith G, Schneider M, Minder C. Bias in meta-analysis detected by a simple, graphical test. BMJ. 1997;315:629-34.

49. Sterne JAC, Sutton AJ, loannidis JPA, Terrin N, Jones DR, Lau J, et al. Recommendations for examining and interpreting funnel plot asymmetry in meta-analyses of randomised controlled trials. BMJ. 2011;343:d4002.

50. StataCorp. 2011. Stata Statistical Software: Release 12. College Station, TX: StataCorp LP.

51. Porrata LF, Ristow K, Habermann TM, Witzig TE, Colgan JP, Inwards DJ, et al. Peripheral blood lymphocyte/monocyte ratio at diagnosis and survival in nodular lymphocyte-predominant Hodgkin lymphoma. Br J Haematol. 2012a; 157:321-30.

52. Porrata LF, Ristow K, Colgan JP, Habermann TM, Witzig TE, Inwards DJ, et al. Peripheral blood lymphocyte/monocyte ratio at diagnosis and survival in classical Hodgkin's lymphoma. Haematologica. 2012b:97:262-9.

53. Koh YW, Jung SJ, Yoon DH, Suh C, Cha HJ, Go H, Kim JE, Kim CW, Huh J. The absolute lymphocyte to monocyte ratio is associated with poor prognosis in classical Hodgkin lymphoma patients younger than 60 years of age. Hematol Oncol. 2015;33:133-40.

54. Tadmor T, Bari A, Marcheselli L, Sacchi S, Aviv A, Baldini L, et al. Absolute monocyte count and lymphocyte-monocyte ratio predict outcome in nodular sclerosis Hodgkin lymphoma: evaluation based on data from 1450 patients. Mayo Clin Proc. 2015;90:756-64.

55. Simon Z, Barna S, Miltenyi Z, Husi K, Magyari F, Jona A, Garai I, Nagy Z, Ujj G, Szerafin L, Illes A. Combined prognostic value of absolute lymphocyte/ monocyte ratio in peripheral blood and interim PET/CT results in Hodgkin lymphoma. Int J Hematol. 2016;103:63-9.

56. Vassilakopoulos TP, Dimopoulou MN, Angelopoulou MK, Petevi K, Pangalis GA, Moschogiannis M, et al. Prognostic implication of the absolute lymphocyte to absolute monocyte count ratio in patients with classical Hodgkin lymphoma treated with doxorubicin, bleomycin, vinblastine, and Dacarbazine or equivalent regimens. Oncologist. 2016;21:343-53.
57. Jakovic LR, Mihaljevic BS, Andjelic BM, Bogdanovic AD, Perunicic Jovanovic $\mathrm{MD}$, Babic DD, Bumbasirevic VZ. Prognostic value of lymphocyte/monocyte ratio in advanced Hodgkin lymphoma: correlation with international prognostic score and tumor associated macrophages. Leuk Lymphoma. 2016;57:1839-47.

58. Romano A, Parrinello NL, Vetro C, Chiarenza A, Cerchione C, Ippolito M, Palumbo GA, Di Raimondo F. Prognostic meaning of neutrophil to lymphocyte ratio (NLR) and lymphocyte to monocyte ration (LMR) in newly diagnosed Hodgkin lymphoma patients treated upfront with a PET-2 based strategy. Ann Hematol. 2018;97:1009-18. http://dx.doi.org/10.1007/s00277018-3276-y.

59. Deshmane SL, Kremlev S, Amini S, Sawaya BE. Monocyte chemoattractant Protein-1 (MCP-1): an overview. J Interf Cytokine Res. 2009;29:313-26.

60. Tadmor T, Fell R, Polliack A, Attias D. Absolute monocytosis at diagnosis correlates with survival in diffuse large B-cell lymphoma-possible link with monocytic myeloid-derived suppressor cells. Hematol Oncol. 2013;31:65-71.

61. Montero AJ, Diaz-Montero CM, Kyriakopoulos CE, Bronte V, Mandruzzato S. Myeloid-derived suppressor cells in cancer patients: a clinical perspective. J Immunother. 2012;35:107-15.

62. Romano A, Parrinello NL, Vetro C, Forte S, Chiarenza A, Figuera A, Motta G, Palumbo GA, Ippolito M, Consoli U, Di Raimondo F. Circulating myeloidderived suppressor cells correlate with clinical outcome in Hodgkin lymphoma patients treated up-front with a risk-adapted strategy. $\mathrm{Br} J$ Haematol. 2015;168:689-700.

63. Adams HJA, Nievelstein RAJ, Kwee TC. Systematic review and meta-analysis on the prognostic value of complete remission status at FDG-PET in Hodgkin lymphoma after completion of first-line therapy. Ann Hematol. 2016;95:1-9.

64. Diaz-Jauanen E, Strickland RG, Williams RC. Studies of human lymphocytes in the newborn and the aged. Am J Med. 1975;58:620-8.

65. Sedgwick P. What is publication bias in a meta-analysis? Bmj. 2015;351:h4419.

66. Sedgwick P, Marston L. How to read a funnel plot in a meta-analysis. Bmj. 2015:351:h4718.

67. Hemingway H, Riley RD, Altman DG. Ten steps towards improving prognosis research. BMJ. 2009;339:b4184

68. Biasoli I, Castro N, Delamain M, Silveira T, Farley J, Simões BP, et al: Treatment outcomes for Hodgkin lymphoma: first report from the Brazilian prospective registry. Hematological Oncology:n/a-n/a.

69. Maddi RN, Linga VG, Iyer KK, Chowdary JS, Gundeti S, Digumarti R, Paul TR. Clinical profile and outcome of adult Hodgkin lymphoma: experience from a tertiary care institution. Indian J Med Paediatr Oncol. 2015;36:255-60.

Ready to submit your research? Choose BMC and benefit from:

- fast, convenient online submission

- thorough peer review by experienced researchers in your field

- rapid publication on acceptance

- support for research data, including large and complex data types

- gold Open Access which fosters wider collaboration and increased citations

- maximum visibility for your research: over $100 \mathrm{M}$ website views per year

At BMC, research is always in progress.

Learn more biomedcentral.com/submissions 